University of Nebraska - Lincoln

DigitalCommons@University of Nebraska - Lincoln

Fall $11-1-2020$

Electronic Resource Management System Needs and Problems: A Study on Perceptions of Library Professionals on the Use of CORAL

Saurabh Karsanbhai Prajapati Mr

Institute of Rural Management Anand, saurabh@irma.ac.in

Nimesh D. Oza Dr.

Sardar Patel University, oza_nd@yahoo.co.in

Follow this and additional works at: https://digitalcommons.unl.edu/libphilprac

Part of the Library and Information Science Commons

Prajapati, Saurabh Karsanbhai Mr and Oza, Nimesh D. Dr., "Electronic Resource Management System Needs and Problems: A Study on Perceptions of Library Professionals on the Use of CORAL" (2020). Library Philosophy and Practice (e-journal). 4366.

https://digitalcommons.unl.edu/libphilprac/4366 


\title{
Electronic Resource Management System Needs and Problems: A Study on Perceptions of Library Professionals on the Use of CORAL
}

\author{
Dr. Nimesh Oza \\ Head, Department of Library and Information Science, Sardar Patel University, \\ Vallabh Vidyanagar, Gujarat, India \\ Email: oza_nd@yahoo.co.in \\ Mr. Saurabh Prajapati \\ Deputy Librarian, Institute of Rural Management Anand, Gujarat, India \\ Email: saurabh@irma.ac.in
}

\begin{abstract}
:
The COVID19 pandemic has adversely affected the library environment and its services. Since academic institutions are closed, librarians are forced to adopt more electronic contents to meet the need of users. Managing the complexity of eResources is another great challenge for the librarians. As existing Library Management Software is incompetent to manage the entire life cycle of electronic resources, open source electronic resource management system products are rapidly gaining momentum around the globe. In this context, the present research study examines the library practices regarding the use of CORAL an open source electronic resource management (ERMS) for the effective management of subscribed eResources in their respective libraries nationwide. The paper also investigates the problems and challenges faced by the library while installing and using CORAL ERMS. It also analyses the overall perception of Library Professionals towards the CORAL and the level of satisfaction with the features, functions and different modules of CORAL ERMS. The lion's share of the Library Professionals is satisfied with the CORAL. However, due to lack of vendor support and shortage of skilled workforce, the software is getting less attention across the library professionals than it deserves.
\end{abstract}


Keywords: Electronic Resource Management System (ERMS), CORAL, Open Source ERMS, Automation, Electronic Resource Management Life Cycle, Licensing, Usage Statistics

\section{Introduction:}

The Digital Library Federation (DLF) Electronic Resource Management Initiative (ERMI) has come with a report in 2004 which acted as a catalyst not only for the librarians but also for the publishers and commercial vendors as well. An initiative has been taken by the publishing industries, aggregator database providers and libraries for development of electronic resource management system, functionality and providing the finest solutions to the effective management of electronic resources. Most of the ERM tools have been made available by them in the market after 2003. All these ERMS have come up under four major categories.

1. Open Source Electronic Resource Management System

2. Proprietary Electronic Resource Management System

3. Homegrown Electronic Resource Management System

4. Integrated Library Management System

1.1 What is Open Source Electronic Resource Management System: There is a variety of proprietary and homegrown software available for the management of electronic resources. However, given today's constraints of budget, the trends towards the adoption of open source software in different types of libraries are increasing gradually. As of now a minimal number of open source ERMS available in the market. The details of the same are as below:

Example of Open Source ERMS Products: 
口 CORAL (http://coral-erm.org/)

口 E-Matrix (https://www.lib.ncsu.edu/e-matrix/contact.html)

口 ERMEs (http://murphylibrary.uwlax.edu/erm/)

$\boldsymbol{\square}$ reSearcher (https://www.lib.sfu.ca/about/initiatives/researcher)

글 Semper Tool Digital Library Suit (https://www.sempertool.dk/services)

1.2 What is Proprietary Electronic Resource Management System: Many renowned publishers and service providers have put in significant resources and devoted substantial time in developing an electronic resource management system as per the need of the Libraries. This ERM System is also called as ERM Tools, which can manage the entire life cycle and workflow of electronic resources such as Trial, Selection, Acquisition, Provide Access, Licensing, Troubleshooting, Usage Statistics and Renewals. Most of the proprietary ERMS are available to the libraries on payment basis. Sometimes they also operate on a subscription model; in other words, software as a service (SAAS). However, many ERMS Vendor also charges a one-time for initial setup and as installation fees.

The details of current proprietary ERMS are given below:

Few Examples of Proprietary ERMS Products:

口 EBSCONET Subscription Management (https://www.ebsco.com/products/ebsconet-

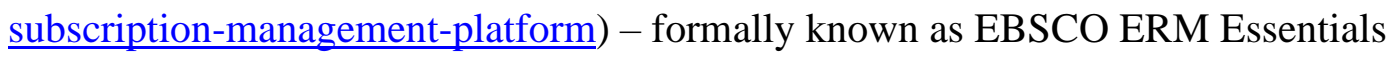

TDNet Discover (https://tdnet.io/services/discovery)

Gold Rush (https://www.coalliance.org/software/gold-rush) 


\subsection{What is Homegrown Electronic Resource Management System: Many}

Institutional and University Libraries have developed in-house based electronic resource management system based on the specific need of their respective libraries. Since it is designed and developed in-house, it is called homegrown ERMS. In most of the cases, these kinds of ERMS are not shared outside of the organizations.

Example of Homegrown ERMS:

口 HERMES: The Hopkins Electronic Resource Management System (https://jscholarship.library.jhu.edu/handle/1774.2/32801)

口 VERA by MIT (http://libraries.mit.edu/vera)

\subsection{Integrated Library Management System}

In the early development stage of ERMS, most of the products were developed as standalone ERM's. But now in the current scenario, the libraries are looking for newer Integrated Library Management System that typically incorporates the core ERM functionality. In other words, Library Professionals are looking for a single system for all library processes. The ALMA (https://www.exlibrisgroup.com/products/alma-library-services-platform/) and FOLIO (https://www.folio.org/) are the best examples of current ILMS.

In India, the trends towards the development of digitization and adoption of an electronic resource are snowballing, especially in academic libraries. The libraries discontinue print collection steadily and subscribe to more electronic contents.

This study attempted to assess the academic library professionals' perception and experience of using CORAL ERMS in their respective library environment for the management of electronic resources. 


\section{Literature Review:}

So far, significantly less has been published about CORAL electronic resource management system. Most of the implementation of CORAL is done by the Libraries in the USA, and these Libraries have shared their experience by case studies on the implementation of an electronic resource management system.

(Drake et al., 2014) in their case study have clearly stated the advantages of CORAL over the other ERMS:

$$
\begin{aligned}
& \text { "CORAL's interface was straightforward and intuitive to navigate. It had all } \\
& \text { the basic functionality and could also accommodate multiple types of e- } \\
& \text { resources, through multiple platforms and from multiple vendors. The } \\
& \text { system was built modularly with interconnected parts, so it could be used in } \\
& \text { part or completely and reduced the need for duplicate data entry. Within the } \\
& \text { system's administrative functions, there was room for customization. And in } \\
& \text { addition, when we looked at the CORAL community, we found potential } \\
& \text { advantages." }
\end{aligned}
$$

(Imre et al., 2013) in their case study reported the experience of three libraries with CORAL. All three libraries reported that CORAL ERM is versatile and easy to set up as per the need of the libraries. However, they state that there are several areas where it is possible to enhance CORAL, and since it is a low-cost solution, it was popular amongst these libraries.

(Hartnett et al., 2013) sagely remarked, "Despite the number of proprietary and open-source options available, these presentations and discussions indicate that, finding the Holy Grail might be easier than finding the perfect ERMS". The authors have highlighted their two unsuccessful attempts of implementation of the electronic resource management system and 
narrated their experience of successful implementation of CORAL ERM by documenting the process of selection, planning, implementation including future plans for this system.

The literature on CORAL ERM implementations yields very little about ERMS within the system. In one of the recent invited articles (Song et al., 2019) wrote that "CORAL is an open source electronic resource management system and any library can install and use this ERMS to track information about electronic subscriptions, including resource and licensing information, cost history, acquisitions information, vendor contacts, and usage statistics."

\section{CORAL ERMS:}

CORAL stands for Centralizes Online Resource Acquisition and Licensing, is a free and open source ERM Tool, basically designed and developed to manage the entire life cycle and workflow of electronic resources. This software is available under a General Public License (GPL) V.3 which was developed initially by Hesburgh Libraries at the University of Notre Dam, United States of America. The CORAL runs on a server application that is open source: MySQL 5.5 or MariaDB 10 and above; PHP 5.5 or above and Apache 2.2 or above. Currently, CORAL ERMS is being used by many libraries around the world for effective management of subscribed electronic resources.

The core beauty of CORAL ERMS is its interoperable modules which are designed around the core components of electronic resource management system lifecycle. The CORAL ERMS has five major modules which can be installed and use individually or as complete package. The five modules consist of:

1. Resources: The Resources Module aids in organizing your order and resource information. 
2. Licensing: The Licensing Module helps arrange and archive your licensing agreements.

3. Organizations: The Organizations Module assists you in managing the contact and account information for vendors, consortia and publishers.

4. Usage Statistics: The Usage Statistics Module provides a solution for usage statistic of electronic collection from a COUNTER and SUSHI supported publishers.

5. Management: The Management Module offers a conveniently accessible storage space where you can store and arrange all records related to eResources. Such as: Policies, Workflows, Procedures and so on.

\section{Rational of the study:}

The rapid growth in electronic contents has enforced librarians to think about the smart mechanism to facilitate the workflow processes of subscribed electronic resources. Since current Library Management Software (LMS) are not capable enough to handle the management of electronic resources effectively or holistically, libraries are looking for a system which helps them to manage the entire life cycle of electronic resources. Since open source is a cost effective solutions for most of the libraries these days, the author chooses to examine the CORAL ERMS for the study. A few studies have been reported, but they are very old. This research study has attempted to give a current up to date picture of library professionals' perceptions regarding the use of CORAL electronic resource management system. It also tries to bring out different ways and means to create awareness amongst the library professionals about the concept of ERMS, especially in India. 


\section{Professionals Satisfaction Studies:}

The study relating to the satisfaction of Librarians with regards to open source ERMS CORAL is useful not only for the Libraries who are planning to implement ERMS but also will be helpful to the CORAL Community to improve the system.

\section{Objectives of the Study}

The primary objective of the present study is to assess the perception of library professionals towards the use of CORAL ERMS across the selected nations. The specific objectives are as follows:

1. To assess library professionals' perception of open source electronic resource management "CORAL".

2. To find out the PRE-ERMS conditions of the libraries.

3. To identify the perceived challenges faced by the library professionals in the absence of ERMS.

4. To investigate the extent of satisfaction of the library professionals with the functional modules of the CORAL ERM software.

5. To get suggestions from the academic library professionals across the nations for improving open source ERMS CORAL.

\section{Significance of the study:}

There have been minimal articles available on CORAL electronic resource management system. Academic libraries in the USA have done a few case studies and published a paper on the same. Most of the articles on CORAL have been published between 2004 till 2013. After that, no single studies have been done in this area. This study intends to fill the research gap by conducting a worldwide survey on CORAL ERMS. A selected academic library who 
have installed CORAL and implemented were invited to share their invaluable experience as well as perception about CORAL ERMS. The authors hope that the research output will provide further directions to the CORAL Community, especially to the developers of CORAL software.

\section{Scope and Limitations of the Study:}

In total, twenty-five libraries from the different parts of the continents were invited to take part in this qualitative survey. The list of these libraries has been received from the CORAL Community Forum. Libraries from the USA have been given more weightage as maximum number implementations of ERMS are done in the USA. For this study, all twenty-five participating libraries chose to remain anonymous, so that they could be as truthful and unimpeachable as possible.

The present study does not attempt to explore specific types or genre of the library and geographical sphere, as it was focused to assess and fetch out the penetration of ERMS implementation for the management of electronic resource across the nations.

\section{Methodology:}

The population for this survey was the libraries that are using CORAL as their electronic resource management system. A purposeful sample of twenty-five libraries using CORAL was selected. This study is entirely based on the survey method. The data was collected by conducting an online survey through the Google Form. The authors have prepared an online questionnaire and were distributed to the selected library professionals through email. The questionnaire mainly focused on Installation and use of CORAL Modules, the problems and challenges faced while using CORAL and the level of satisfaction with CORAL ERMS etc. 
In light of the study's core objectives, the data obtained through the survey were analyzed and interpreted in subsequent section.

\section{Data Analysis and Interpretation:}

\section{a. Type of Library:}

From Google From, all the responses were plotted in Microsoft Excel for detailed analysis. The basic calculation has made, and the same has been represented in the form of graphs and charts for clear understanding. Figure 1 shows that 25 questionnaires were sent to different types of libraries that had installed CORAL electronic resource management system and used it. Majority of the selected libraries were academic libraries (88\%). In contrast, the remaining installation and use of CORAL ERMS were chosen from the special library, library technology service provider, and consortium for eResources, i.e. (4\%).

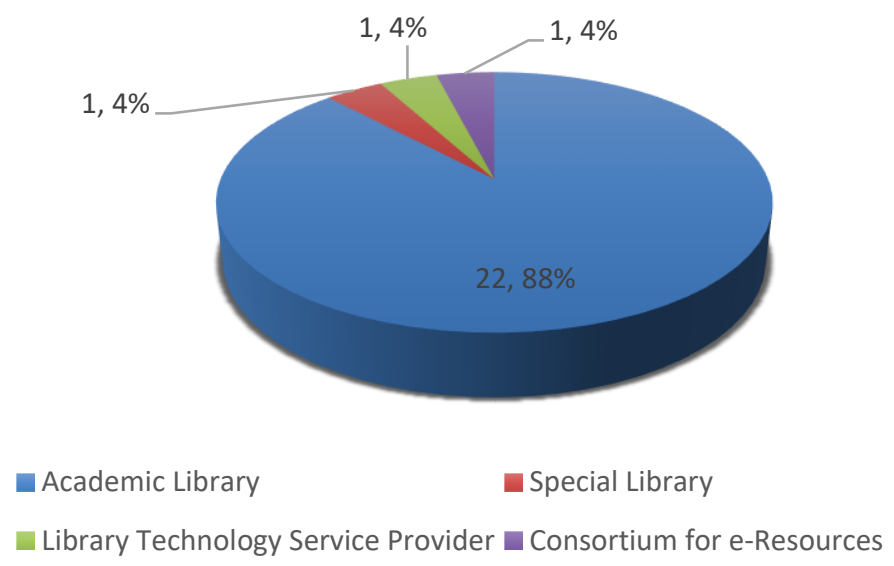

Figure 1. Type of Library

\section{b. Demographics:}

In Figure 2, we present the name of countries in which their libraries are using CORAL as ERMS, and the library professionals from these countries have actively participated in this survey. 


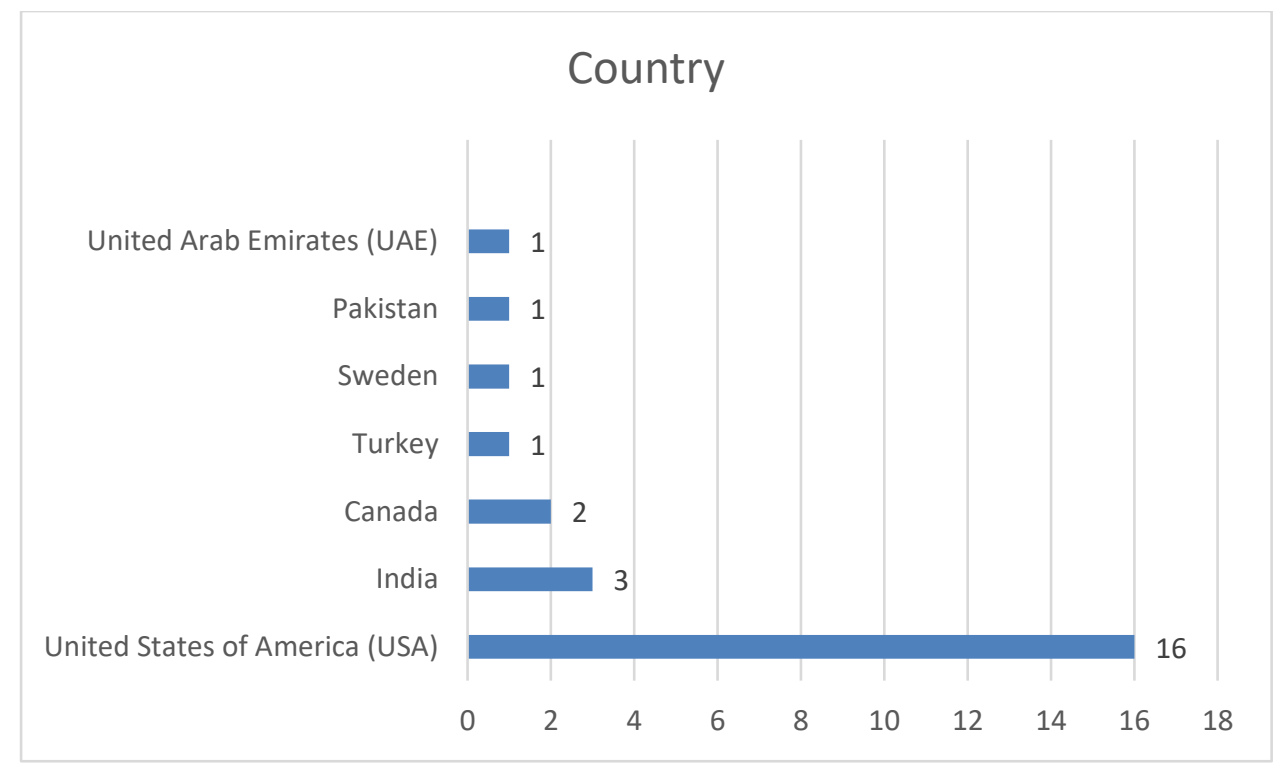

Figure 2. Name of countries participated in the survey

\section{c. Pre-ERM Condition:}

It is important to know the PRE-ERM conditions in the libraries. Thus, the authors have also explored how electronic resources were managed and what are the problems and challenges faced by the libraries in the absence of the ERM System.

Figure 3 demonstrates the ways and means used by the library professionals to manage their electronic contents in the absence of dedicated ERMS. The majority of the libraries that do not have ERMS were using Microsoft Excel (72\%), a good number of respondents were also using email (48\%) followed by Integrated Library Management System (ILMS) (40\%) and Manual Paper Files (32\%). Other less used methods reported by the respondents were Digital Library Management System (DLMS) (8\%), and the respondents reported minimal use of Homegrown System (4\%), Microsoft Access (4\%), Paper Files (4\%) and Subscription Agent System (4\%). 
How electronic resources and its subscriptions were managed before ERMS Implementation.

25 responses

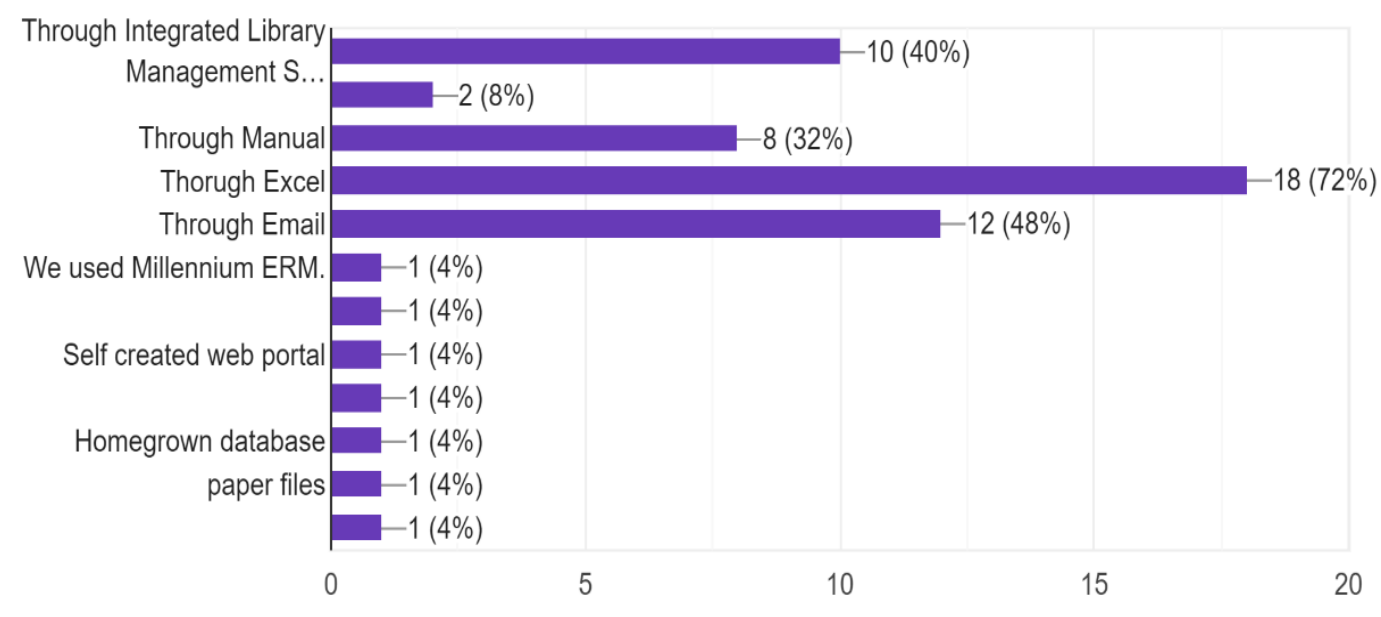

Figure 3. How Electronic Resources are managed in the absence of CORAL ERMS

The analysis indicated that despite automation and having Library Management System (LMS) in place, the majority of the respondents were managing their electronic resources manually as pure library management software are not capable enough to handle the entire lifecycle of electronic resources.

\section{d. Problems and challenges in the absence of ERMS:}

It is observed that the Electronic Resource Management System (ERMS) is significant and has a crucial role to play. There are numerous issues which were faced by the libraries in the absence of ERMS. Majority of the respondents, nearly $88 \%$ (22) expressed that, management of License agreement was found to be most challenging in the absence of dedicated ERMS. However, other problems like tracking of purchasing history of eResources $68 \%$ (17), storing and retrieving contact details of publishers and vendors 52\% (13), managing multiple journals packages $52 \%$ (13) and smooth renewals of eResources $48 \%$ (12) are the major issued reported due to unavailability of the ERMS. 


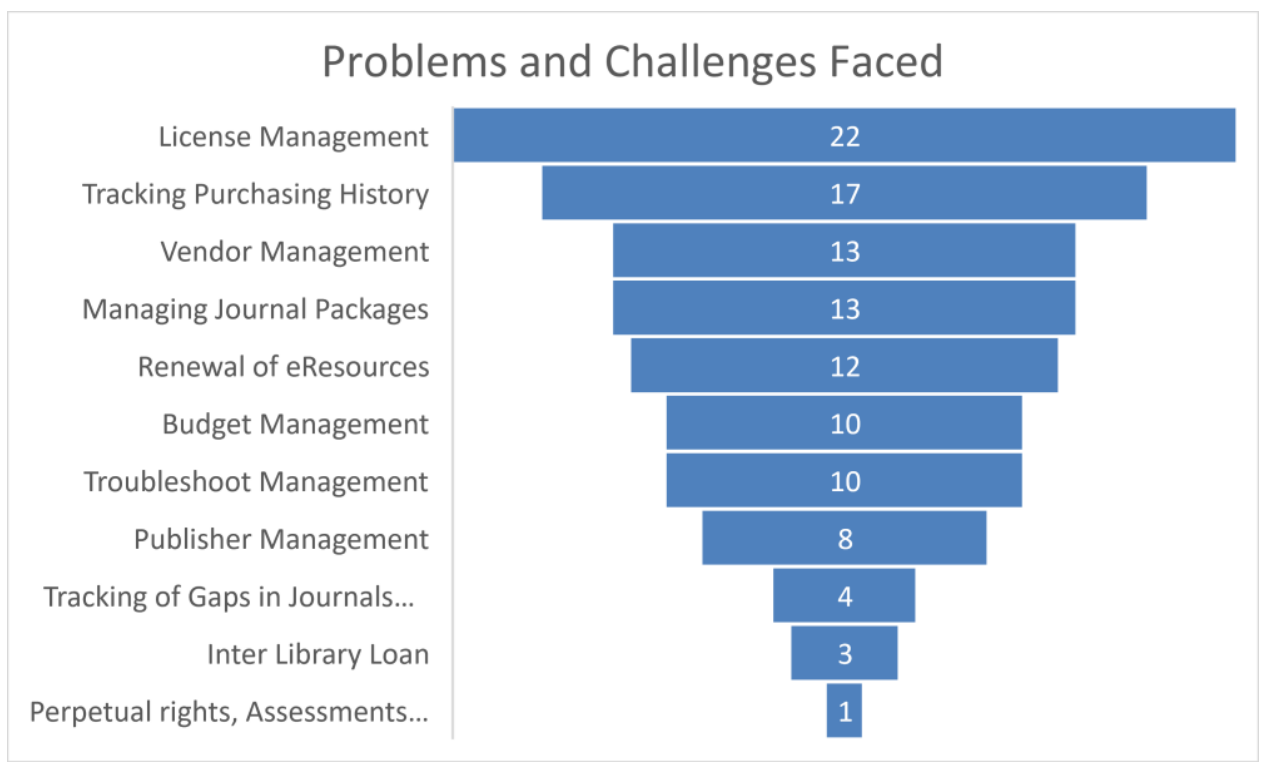

Figure 4. Problems and Challenges Faced by Libraries in the absence of ERMS

It is assumed that most of the libraries are following reactive approach for troubleshooting management. Troubleshoot Management 40\% (10) and Budget Management 40\% (10) have reported equally by the respondents when it comes to managing eResources without ERMS. With the use of dedicated ERMS, library professionals can adopt a pro-active approach for troubleshooting and provide uninterrupted services to the users. Other factors such as Tracking of Gaps in Journals 16\% (8), ILL 12\% (4), Tracking of Perpetual Rights 4\% (3) were found to be fewer problematics as far as management of electronic resources without ERMS is concerned.

It indicates that there is a dire need of electronic resource management system for effective management of electronic resources in the library.

\section{e. A version of CORAL:}

Since inception till date, the CORAL has released three different versions. The current latest version of CORAL is 3.X. Figure 1. Shows $64 \%$ of the Libraries have been using CORAL 3.X latest version followed by $24 \%$ CORAL 2.X and only $12 \%$ CORAL $1 . X$. 


\section{VERSION OF CORAL}

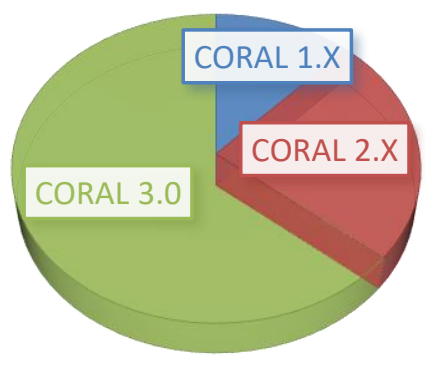

Figure 5. A version of CORAL Installed and Used by the Libraries

Library professionals are always recommended to use the current latest version of CORAL for advance features and functionality. Upgradation from old version to new version is also available in CORAL.

\section{f. Use of different modules of CORAL:}

Since CORAL provides flexibility, the authors have tried to understand the installation and usability of the modules by the libraries. Figure 6 depicts the name of modules extensively used the libraries. While analyzing CORAL modules, it was observed that out of 25 respondents, $100 \%$ (25) professionals had installed Organization Module followed by $96 \%$ (24) Resource and Licensing modules and explored them whereas Management (36\%) and Usage Statistics (32\%) modules were less used /popular amongst the respondents.

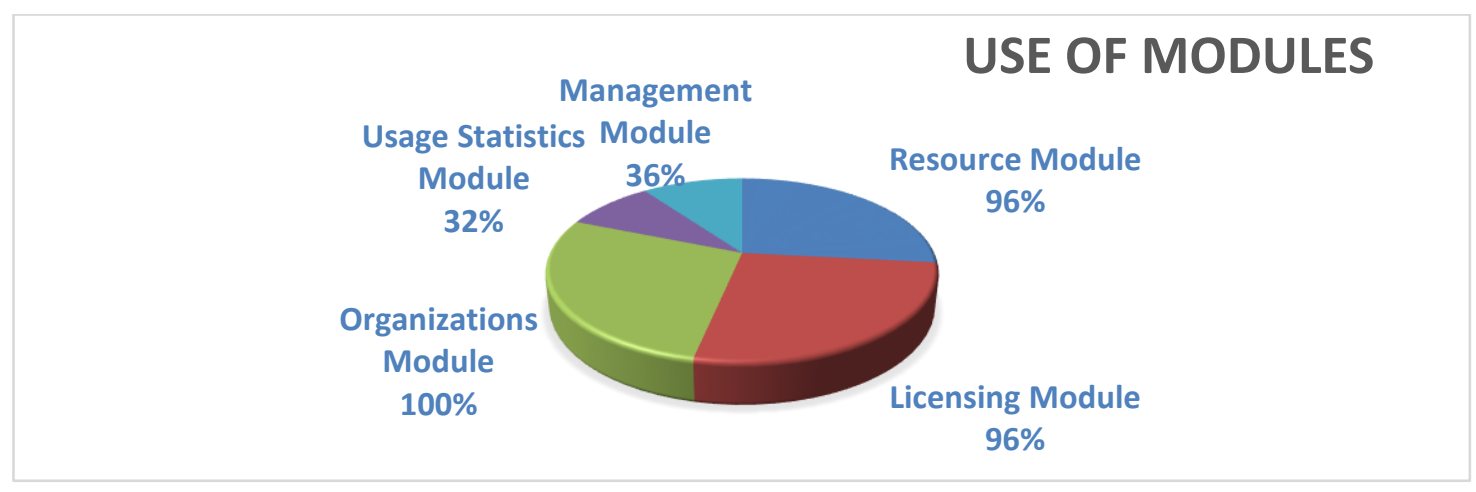

Figure 6. Which are the modules used by the Libraries 


\section{g. Level of satisfaction with CORAL modules:}

This study explored how satisfied library professionals were with the performance of the resource module, license module, organizations module, usage statistics module and management module of CORAL ERMS while indicating that they had big concerns about the usage statistics module. Almost certainly the CORAL usage statistics module needs improvements.

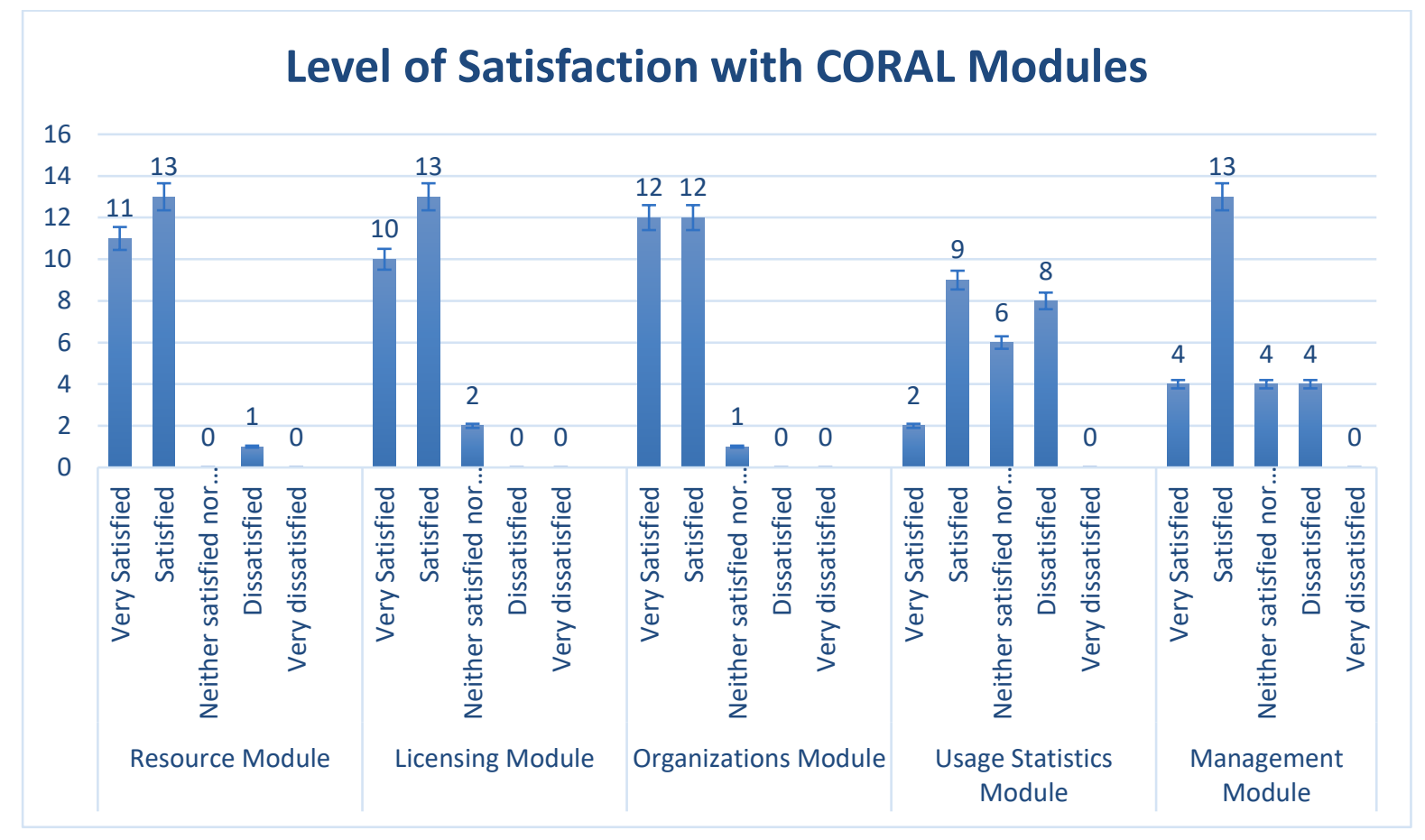

Figure 7. Satisfaction Level of Libraries in using CORAL

Figure 7 reveals that the majority of the librarians remarked Resource Module (11), Licensing Module (10) and Organizations Module (12) are excellent. Since all CORAL modules are designed to meet the complete life cycle of electronic resources, it helps libraries to manage all subscribed electronic resources in one platform effectively. 


\section{h. Overall satisfaction with CORAL ERMS:}

The Librarians using CORAL ERMS for their respective libraries were asked to rate this ERMS on different aspects based on the experience they had with the software. The survey reveals that most of the CORAL users were shown a positive attitude on various elements due to several reasons. Modules, Layout and Architecture of the CORAL being the foremost reasons which are the main part of the primary concern of any system or software.

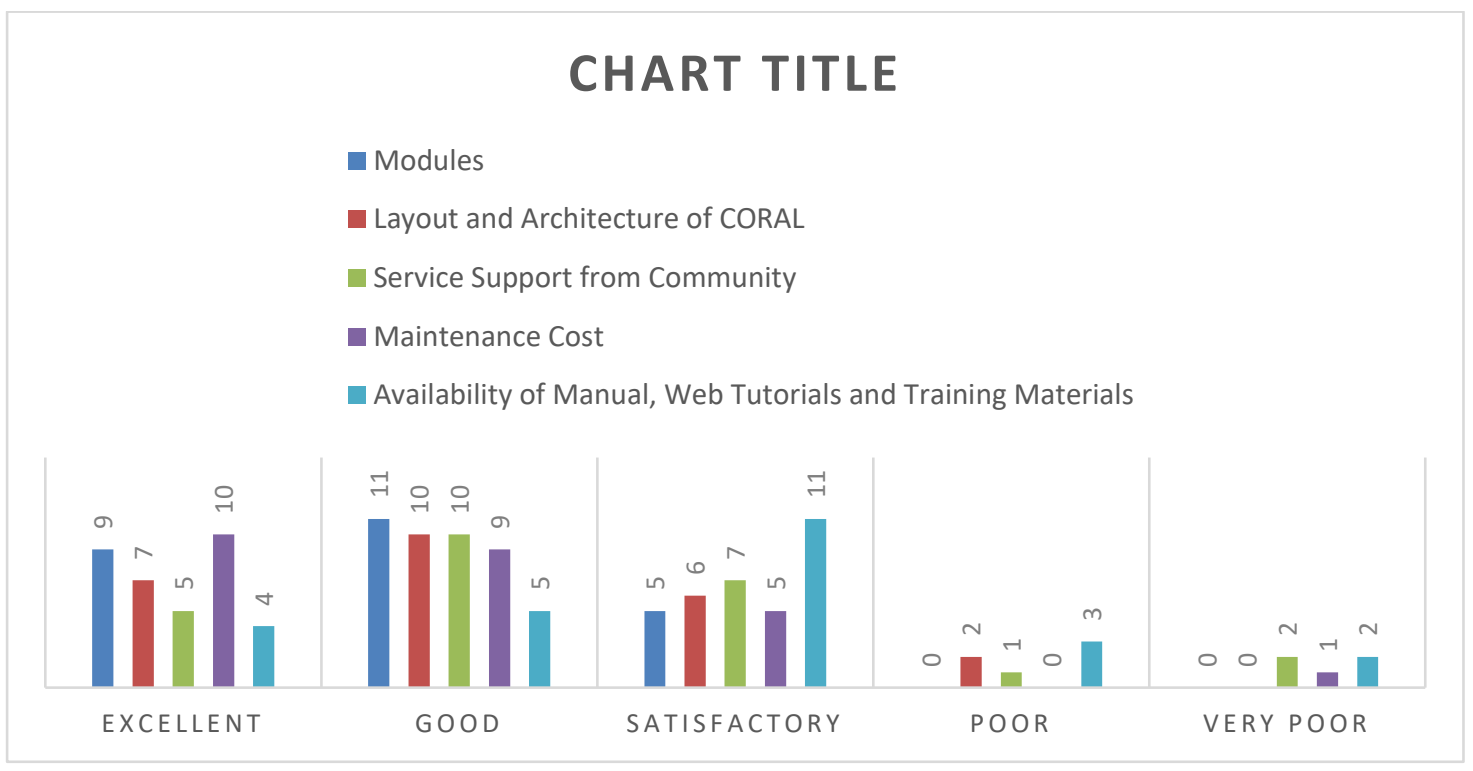

Figure 8. Overall rating of CORAL in different aspects

Though CORAL is open source ERMS, lack of Service support from Community and unavailability of proper documentation, tutorials and training prevent librarians not to use CORAL as their electronic resource management system.

\section{General Comments of the Respondents:}

1. The integration with other open source LMS services needs to be developed quickly, such as with Koha.

2. More Knowledge Base integration, development of cost functions to better support budget management, development of statistics module (it's useless today), 
development of search function in resource module (good possibilities to search but not a very nice search interface), nicer interface overall.

3. A dashboard should be there for Collections Analysis.

4. A field for responsible person (per resource) in resource module, note fields in license module, visible note fields in workflows.

5. The budget component needs improvement. INR Currency with calculation should be there.

6. Ability to import data rather than manual updates.

7. The Terms Tool feature of the Licensing Module needs to be searchable.

8. It works well enough for storing licenses. It has a few bugs - sometimes a file will not upload, the Terms Tool is not searchable.

9. Better integration with ILS or catalogue systems.

10. Should have the ability to export pricing history in separate lines in Excel.

11. Usage Statistics Module need Improvements. Make usage statistics work! (To be honest, it never worked right in the Millennium ERM either). Financial tie-in with Koha ILS, which also needs a lot of help on the Acquisitions side.

12. Usage statistics don't work, manual or SUSHI. Need a way to send email reminders for renewing resources. Better (more detailed) import of order information.

13. Add more notes fields. Expand capability of usage statistics module to accept more reports, including non-COUNTER reports.

14. Rich user interface, implementation of charts for usage report.

15. More technical support -- want it to work "out of the box."

16. Making the Terms Tool feature of the Licensing Module searchable.

17. More Live Training on How to Use CORAL and Community Support for technical queries for Multilanguage. 
18. It meets our basic needs and is easy to use, but improvements can be made both with existing functions within Coral and regarding development to better support all the tasks related to e-resources.

19. Good initiative by the CORAL team, Response time for user queries needs to be addressed quickly.

20. CORAL is useful and cost-effective. It helps to have content all in one place and easy access to order history. The ability to add notes to the order history helps with understanding why pricing has changed over time.

\section{Conclusions and Recommendations:}

Electronic Resource Management System (ERMS) in the current context has become an essential tool to manage subscribed electronic contents in the library. The success of implementing ERMS is highly depends on the skilled professional's workforce, proper creation of workflow, availability of requisite hardware and software support and last but not the lease the positive approach, acceptance and adoption of professional library staffs.

The authors have found that the majority of the libraries were dissatisfied with the performance of the usage statistics module. Overall, the survey results demonstrate that the libraries that had implemented and used CORAL for the management of their subscribed electronic resources have reported positive approach. The findings of the study also reveal that CORAL is useful and cost effective practical ERM Solution for types of libraries, including academic universities and institutional libraries. However, some significant issues associated with CORAL ERMS users are lack of technical support, lack of vendor support, a response time of user queries by CORAL community, lack of awareness, pricing history and multicurrency option and integration of CORAL with Library Management Software needs to be addressed quickly. 
The analysis draws an inference stating that the use and implementation of CORAL ERMS in Libraries require a thorough knowledge of electronic resource Lifecycle, workflow and technical expertise, thus advance planning and proper roadmap is needed before selecting and implementing electronic resource management system in the library.

The outcomes of this study analysis lead to the following recommendations:

1. Libraries with limited library budget should use CORAL open source electronic resource management for managing subscribed electronic contents.

2. The CORAL Community should frequently organize short term live training programs and workshops on installation and use of CORAL.

3. CORAL should be integrated with open source library management system such as KOHA so that the library can have a single platform (ILMS) for management of all types of resources.

4. Just like CORAL community, ILMS community can be created, and they may promote the advocacy of ILMS for the solution of effective and efficient management of all library resources.

5. The overall framework of international standards should be developed for the integrated library management system (ILMS).

\section{References:}

Clark, C. (2018). New version of coral erm. Journal of Electronic Resources Librarianship, 30(2), 99. https://doi.org/10.1080/1941126X.2018.1465521

CORAL. (2015). CORAL Usage Statistics User Guide. Retrieved from http://coralerm.org/about/ CORAL Terms Tool User Guide. (n.d.). Retrieved October 25, 2015 from http://coral-erm.org/wp-content/uploads/2015/08/CORAL-Usage-Stats-User- 
Guide.pdf

CORAL. (2015). Terms Tool User Guide. http://docs.coral-erm.org/en/latest/terms.html

Drake, B. K., Geller, M., Wentz, E., \& Choy, L. (2014). When the Open Source System is the Best System. FOSS4LIB (Free/Open Source Software for Libraries).

Hartnett, E., Beh, E., Resnick, T., Ugaz, A., \& Tabacaru, S. (2013). Charting a Course through CORAL: Texas A\&amp;M University Libraries’ Experience Implementing an Open-Source Electronic Resources Management System. Journal of Electronic Resources Librarianship. https://doi.org/10.1080/1941126X.2013.760402

Imre, A., Hartnett, E., \& Hiatt, C. D. (2013). CORAL: Implementing an Open-Source ERM System. Serials Librarian, 64(1-4), 224-234. https://doi.org/10.1080/0361526X.2013.760414

Mi, J., \& Wang, Y. (2013). Implementation and Application of CORAL: An Open Source ERM System. Collection Management, 38(1), 75-79. https://doi.org/10.1080/01462679.2012.730493

Song, X., Tatterson, R., \& Dresselhaus, A. (2019). CORAL User Group Meeting at NC Serials 2019. Serials Review, 45(3), 126-131. 